Article

\title{
Dihydrodinophysistoxin-1 Produced by Dinophysis norvegica in the Gulf of Maine, USA and Its Accumulation in Shellfish
}

Jonathan R. Deeds ${ }^{1, *}$, Whitney L. Stutts ${ }^{1, \dagger}{ }^{\text {, Mary Dawn Celiz }}{ }^{1}$, Jill MacLeod ${ }^{2}$, Amy E. Hamilton ${ }^{2, \ddagger}$, Bryant J. Lewis ${ }^{2}$, David W. Miller ${ }^{2}$, Kohl Kanwit ${ }^{2}$, Juliette L. Smith ${ }^{3}$, David M. Kulis ${ }^{4}$, Pearse McCarron ${ }^{5}$, Carlton D. Rauschenberg ${ }^{6}$, Craig A. Burnell ${ }^{6}$, Stephen D. Archer ${ }^{6}$, Jerry Borchert ${ }^{7}$ and Shelley K. Lankford ${ }^{8}$

1 Office of Regulatory Science, United States Food and Drug Administration, Center for Food Safety and Applied Nutrition, College Park, MD 20740, USA; wlstutts@ncsu.edu (W.L.S.);

MaryDawn.Celiz@fda.hhs.gov (M.D.C.)

2 Maine Department of Marine Resources, West Boothbay Harbor, ME 05475, USA;

Jill.MacLeod@maine.gov (J.M.); Amy.Hamilton@maryland.gov (A.E.H.); Bryant.J.Lewis@maine.gov (B.J.L.);

David.W.Miller@maine.gov (D.W.M.); Kohl.Kanwit@maine.gov (K.K.)

3 Virginia Institute of Marine Science, College of William and Mary, Gloucester Point, VA 23062, USA; jlsmith@vims.edu

4 Department of Biology, Woods Hole Oceanographic Institute, Woods Hole, MA 02543, USA; dkulis@whoi.edu

5 Biotoxin Metrology, National Research Council Canada, Halifax, NS B3H 3Z1, Canada; Pearse.McCarron@nrc-cnrc.gc.ca

6 Bigelow Analytical Services, Bigelow Laboratory for Ocean Sciences, East Boothbay, ME 04544, USA; carlton.rauschenberg@gmail.com (C.D.R.); cburnell@bigelow.org (C.A.B.); sarcher@bigelow.org (S.D.A.)

7 Washington State Department of Health, Olympia, WA 98504, USA; Jerry.Borchert@DOH.WA.GOV

8 Washington State Department of Health Public Health Laboratories, Shoreline, WA 98155, USA; Shelley.Lankford@DOH.WA.GOV

* Correspondence: jonathan.deeds@fda.hhs.gov; Tel.: +1-(240)-402-1474

+ Current Address: Molecular Education, Technology, and Research Innovation Center, North Carolina State University, Raleigh, NC 27695, USA.

$\ddagger$ Current Address: Tidewater Ecosystem Assessment, Maryland Department of Natural Resources, Annapolis, MD 21401, USA.

Received: 25 July 2020; Accepted: 17 August 2020; Published: 20 August 2020

\begin{abstract}
Dihydrodinophysistoxin-1 (dihydro-DTX1, (M-H)- $\mathrm{m} / \mathrm{z}$ 819.5), described previously from a marine sponge but never identified as to its biological source or described in shellfish, was detected in multiple species of commercial shellfish collected from the central coast of the Gulf of Maine, USA in 2016 and in 2018 during blooms of the dinoflagellate Dinophysis norvegica. Toxin screening by protein phosphatase inhibition (PPIA) first detected the presence of diarrhetic shellfish poisoning-like bioactivity; however, confirmatory analysis using liquid chromatography-tandem mass spectrometry (LC-MS/MS) failed to detect okadaic acid (OA, (M-H)- $\mathrm{m} / \mathrm{z}$ 803.5), dinophysistoxin-1 (DTX1, $(\mathrm{M}-\mathrm{H})^{-} \mathrm{m} / \mathrm{z}$ 817.5), or dinophysistoxin-2 (DTX2, $(\mathrm{M}-\mathrm{H})^{-} \mathrm{m} / \mathrm{z}$ 803.5) in samples collected during the bloom. Bioactivity-guided fractionation followed by liquid chromatography-high resolution mass spectrometry (LC-HRMS) tentatively identified dihydro-DTX1 in the PPIA active fraction. LC-MS/MS measurements showed an absence of OA, DTX1, and DTX2, but confirmed the presence of dihydro-DTX1 in shellfish during blooms of D. norvegica in both years, with results correlating well with PPIA testing. Two laboratory cultures of D. norvegica isolated from the 2018 bloom were found to produce dihydro-DTX1 as the sole DSP toxin, confirming the source of this compound in shellfish. Estimated concentrations of dihydro-DTX1 were $>0.16 \mathrm{ppm}$ in multiple shellfish species (max. $1.1 \mathrm{ppm}$ ) during the blooms in 2016 and 2018. Assuming an equivalent potency and molar
\end{abstract}


response to DTX1, the authority initiated precautionary shellfish harvesting closures in both years. To date, no illnesses have been associated with the presence of dihydro-DTX1 in shellfish in the Gulf of Maine region and studies are underway to determine the potency of this new toxin relative to the currently regulated DSP toxins in order to develop appropriate management guidance.

Keywords: diarrhetic shellfish poisoning; dihydro-DTX1; Dinophysis norvegica; Gulf of Maine USA

Key Contribution: This work describes the first record of dihydrodinophysistoxin-1, produced by Dinophysis norvegica, in shellfish in the Gulf of Maine USA. Also provided are data on accumulation of this compound in commercial shellfish species as well as preliminary methods of analysis.

\section{Introduction}

Shellfish harvesting closures due to Diarrhetic Shellfish Toxins (DSTs) in excess of the $0.16 \mathrm{ppm}$ total okadaic acid equivalents (OA eq.) regulatory guidance level are a relatively recent occurrence in the United States (US). The first such closure occurred in the state of Texas (Gulf of Mexico region) in 2008 due to a bloom of Dinophysis ovum [1,2]. The first closure in the state of Washington (west coast Puget Sound region) occurred in 2011 due to a mixture of species, primarily D. acuminata [3,4]. On the east coast of the US, a large bloom of D. acuminata prompted a precautionary shellfish harvesting closure in the Potomac River bordering the states of Maryland and Virginia in 2002, but only trace concentrations of DSTs were found [5]. More recently, D. acuminata has been documented in increasing abundance in the Mid-Atlantic region with DSTs in excess of guidance levels in shellfish (non-commercial) occurring sporadically since 2011 [6,7], but to date, no additional shellfish harvesting closures have occurred in this region. In the east coast New England region, limited shellfish harvesting closures have occurred in the Nauset Marsh system in Massachusetts since 2015 due to DSTs from blooms of D. acuminata (M Brosnahan, Woods Hole Oceanographic Institute, personal communication).

Although D. acuminata and D. ovum have been responsible for the majority of diarrhetic shellfish poisoning (DSP)-related shellfish harvesting closures in the US to date, other potentially toxigenic species have been documented in lower abundance, namely D. fortii and D. norvegica [4,7]. In the central coast of the Gulf of Maine, Dinophysis spp. commonly reach peak abundances in the summer months, and when blooms occur, they are typically predominated by D. norvegica (Maine Department of Marine Resources, personal communication). From July 5 to August 29, 2016, a large monospecific bloom of D. norvegica occurred in the Penobscot and Frenchman Bay regions of the central coast of the Gulf of Maine, USA (Figure 1). Multiple samples with cell concentrations $>2000$ cells $\mathrm{L}^{-1}$ were observed with a maximum concentration of 54,300 cells $\mathrm{L}^{-1}$ recorded on July 17 . Shellfish collected from several sites throughout the bloom area were screened using a commercial protein phosphatase inhibition assay (PPIA), which indicated the presence of DSTs in excess of $0.16 \mathrm{ppm}$, prompting a ban on shellfish harvesting on July 20 (Figure 2). Subsequent confirmatory testing using liquid chromatography tandem mass spectrometry (LC-MS/MS) failed to detect OA, dinophysistoxin-1 (DTX1), or dinophysistoxin-2 (DTX2) from samples collected during the bloom. Testing in three additional laboratories using both methods provided the same results, positive by PPIA and negative by LC-MS/MS. Further exploratory testing using liquid chromatography-high resolution mass spectrometry (LC-HRMS) to screen for additional lipophilic shellfish toxins was also negative. Therefore, the harvesting ban was lifted on August 5 and the PPIA results were considered as false positives. 


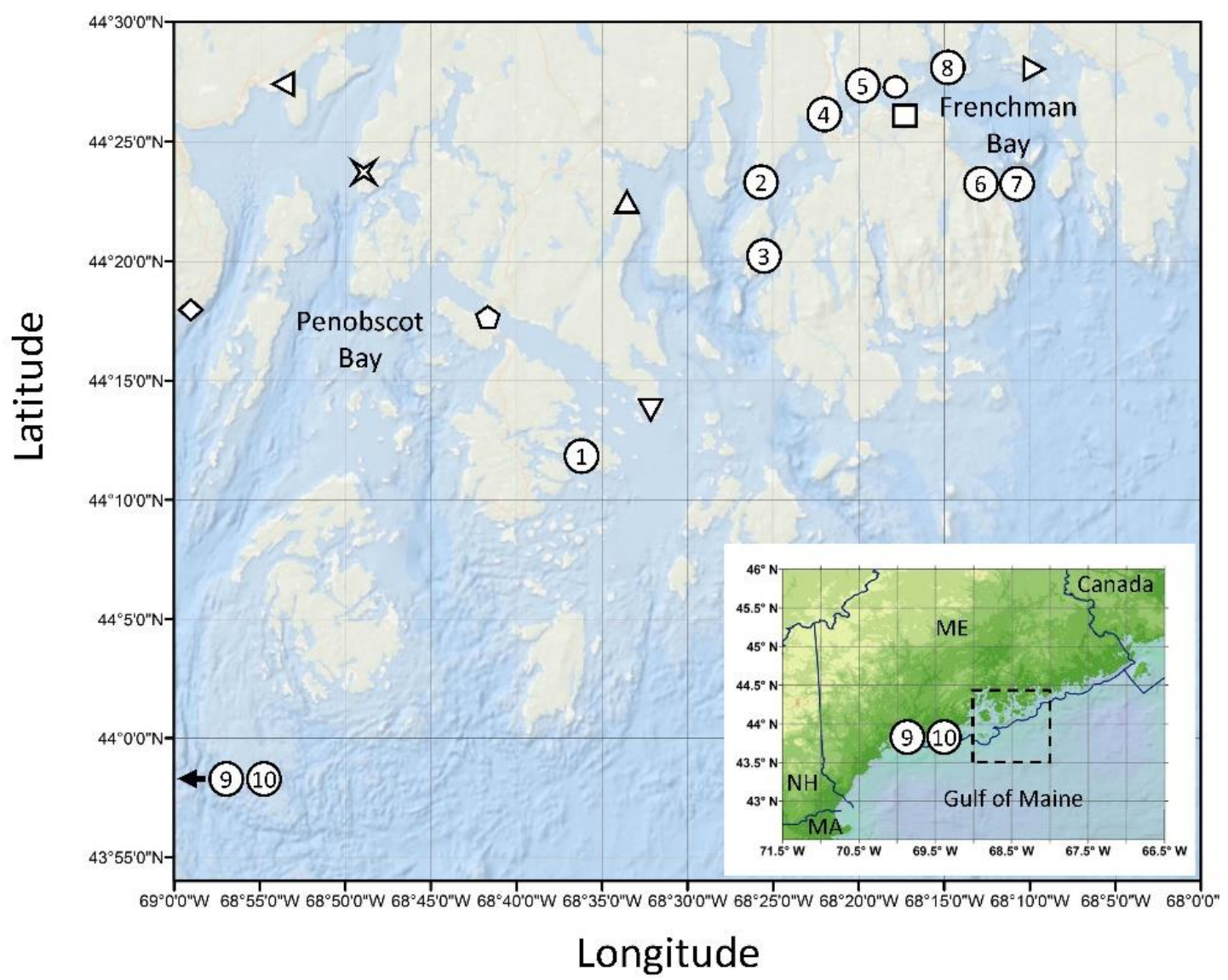

Figure 1. Map of sampling locations during the 2016 Dinophysis norvegica bloom on the central coast of the Gulf of Maine, USA. Symbols indicate sampling locations for both water and shellfish and correspond to data in Figure 2: $[\diamond]$ Lincolnville, $[\triangleleft]$ Searsport, [ $\square$ ] Dice Head, [ $\square$ ] Eggemoggin Reach, $[\triangle$ ] Blue Hill Falls, $[\nabla]$ Flye Point, $[\bigcirc]$ Lamoine State Park, [ $\bullet$ ] Salsbury Cove, $[\triangleright]$ Waukeag. Numbers indicate shellfish sampling only and correspond to data in Table 1: (1) Stinson Neck Causeway, (2) Oak Point, (3) Pretty Marsh Harbor, (4) Trenton Sea Plane Ramp, (5) Googins Ledge, (6,7) Bar Harbor, (8) Raccoon Cove, $(9,10)$ Lumbo's Hole (control site outside of bloom area). Abbreviations: ME-Maine, NH—New Hampshire, MA-Massachusetts. Sampling site coordinates provided in Table S1.

In 2017, an investigation was initiated to determine the source of the DST-like bioactivity occurring in shellfish harvested during blooms of D. norvegica in Maine. Further testing using several commercial enzyme-linked immuno-sorbent assays (ELISAs) specific for DSTs provided the same results as those found by PPIA testing, confirming the presence of compound(s) with both structures and bioactivities similar to DSTs. Bioactivity-guided fractionation identified a single PPIA-positive fraction similar in retention time to DTX1. LC-MS/MS analyses of this semi-purified fraction tentatively identified the unknown DST as dihydro-DTX1. This same compound was identified in additional shellfish samples collected during the D. norvegica bloom in 2016 and again in 2018, as well as in a filtered plankton sample collected in 2018. Finally, this compound was confirmed to be the only DST produced in two cultured isolates of D. norvegica collected from the Gulf of Maine in 2018. Detailed here are the investigations leading to the discovery of this novel DST as well as a proposed strategy to manage this potential new DSP risk until an analytical standard can be produced and the potency of this new toxin in relation to the other known DSTs can be determined. 


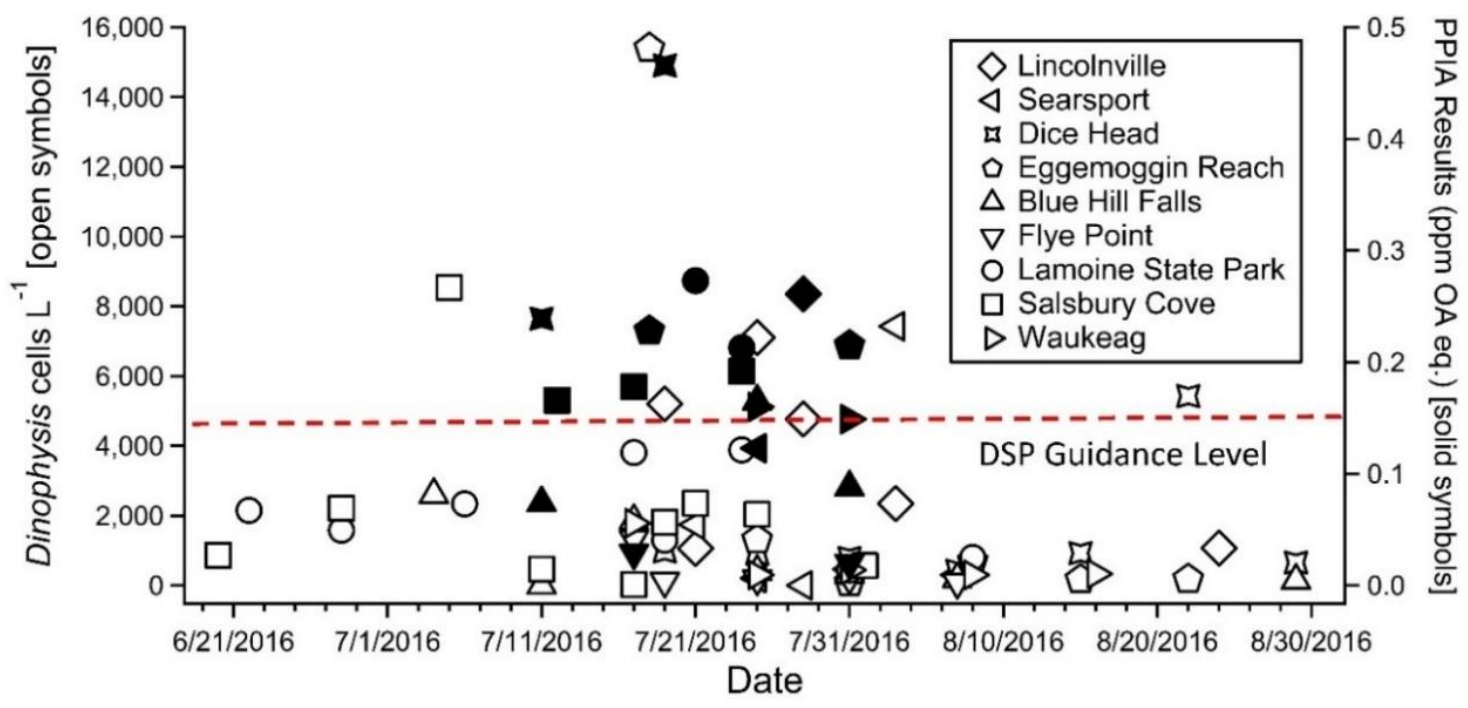

Figure 2. Dinophysis spp. cell counts (open symbols) and corresponding protein phosphatase inhibitory activity (closed symbols) in shellfish collected during the 2016 Dinophysis norvegica bloom in the Gulf of Maine. Dashed line indicates guidance level for DSP toxins in shellfish of $0.16 \mathrm{ppm}$ okadaic acid equivalents (OA eq.). Symbols correspond to sampling sites in Figure 1. Sampling site coordinates provided in Table S1.

Table 1. Results from the analysis for mussel (Mytilus edulis) samples collected during the 2016 Dinophysis norvegica bloom in the Gulf of Maine. (PPIA) protein phosphatase inhibition assay (Okadaic Acid (DSP) PP2A kit, Abraxis Inc., USA), (ELISA) enzyme-linked immuno-sorbent assay (qualitative-NEOGEN Reveal 2.0 for DSP, quantitative-Bioo Scientific MaxSignal Okadaic Acid (DSP)), (LC-MS/MS) liquid chromatography-tandem mass spectrometry performed (1) according to the selected reaction monitoring (SRM) method approved by the National Shellfish Sanitation Program for analyzing clams for OA, DTX1, and DTX2 and (2) with the additional transitions for dihydro-DTX1. All units are in ppm.

\begin{tabular}{cccccc}
\hline \multirow{2}{*}{ Sample $^{\mathbf{a}}$} & \multirow{2}{*}{ PPIA } & \multicolumn{2}{c}{ ELISA } & \multicolumn{2}{c}{ LC-MS/MS } \\
\cline { 3 - 6 } & & Qualitative & Quantitative & OA, DTX1, DTX2 & Dihydro-DTX1 $^{\mathbf{b}}$ \\
\hline $\mathbf{1}$ & 0.20 & Positive & 0.24 & ND & 0.24 \\
$\mathbf{2}$ & $>0.35$ & Positive & 0.67 & ND & 1.08 \\
$\mathbf{3}$ & 0.08 & Negative & 0.08 & ND & 0.06 \\
$\mathbf{4}$ & 0.10 & Negative & 0.07 & ND & 0.07 \\
$\mathbf{5}$ & 0.28 & Positive & 0.34 & ND & 0.79 \\
$\mathbf{6}$ & 0.17 & Positive & 0.16 & ND & 0.20 \\
$\mathbf{7}$ & 0.19 & Negative & 0.14 & ND & 0.21 \\
$\mathbf{8}$ & 0.14 & Negative & 0.15 & ND & 0.16 \\
$\mathbf{9}$ & $<0.06$ & Negative & $<$ LOD & 0.04 DTX1 & ND \\
$\mathbf{1 0}$ & $<0.06$ & Negative & 0.06 & Trace \\
\hline
\end{tabular}

a Numbers correspond to sampling locations shown in Figure 1: (1) Stinson Neck Causeway, (2) Oak Point, (3) Pretty Marsh Harbor, (4) Trenton Sea Plane Ramp, (5) Googins Ledge, (6,7) Bar Harbor, (8) Raccoon Cove, $(9,10)$ Lumbo's Hole (control site outside of bloom area). Sampling site coordinates provided in Table S1. ${ }^{b}(\mathrm{M}-\mathrm{H})^{-} \mathrm{m} / \mathrm{z}$ 819.5 fragmenting to $\mathrm{m} / \mathrm{z} 255.2$ (for quantification) and 151.1 (for confirmation), quantified using an external DTX1 standard. ND: Not detected. Trace: >LOD $0.2 \mathrm{ppb}$ and $<$ LOQ $0.6 \mathrm{ppb}$.

\section{Results}

\subsection{Initial Testing of Shellfish Collected during the 2016 D. norvegica Bloom in the Gulf of Maine}

The 2016 D. norvegica bloom in the Penobscot and Frenchman Bay regions of the central coast of the Gulf of Maine lasted for approximately two months (July 5th-August 29th) (Figures 1 and 2). During that time, numerous shellfish samples were found to display DST-like activity, based on PPIA 
screening, in excess of $0.16 \mathrm{ppm}$ (Figure 2), but subsequent testing for OA, DTX1, and DTX2 by confirmatory LC-MS/MS analysis could not confirm the presence of these compounds.

In an attempt to resolve this discrepancy, ten initial samples of frozen homogenized mussels (Mytilus edulis) were sent to three additional laboratories for follow-up testing. Eight were samples collected during the 2016 D. norvegica bloom that had all previously tested positive for DST-like activity based on PPIA screening while an additional two samples, collected prior to the bloom and outside of the bloom area, were sent as negative controls. With the exception of one sample, all samples were found to be $<$ LOD for OA, DTX1, and DTX2 by LC-MS/MS testing. All samples were also shown to be $<$ LOD for the additional lipophilic shellfish toxins azaspiracids, pectenotoxins, and yessotoxins as tested using LC-HRMS analysis. The single sample found to contain a detectable concentration of DSTs by LC-MS/MS was actually one of the presumptive negative control samples collected on 6/27/16, prior to the D. norvegica bloom and from south of the bloom area (Sample 10 from Figure 1; 0.04 and $0.05 \mathrm{ppm}$ DTX1 only as tested by two independent laboratories). All samples were re-tested at the FDA Center for Food Safety and Applied Nutrition (CFSAN) by PPIA and LC-MS/MS and results were found to be consistent with previous testing. Further testing using both a qualitative lateral flow ELISA (NEOGEN Reveal 2.0 for DSP) and a quantitative ELISA (Bioo Scientific MaxSignal Okadaic Acid (DSP)) showed results consistent with PPIA testing, suggesting the presence of DST-like compound(s) based on both bioactivity and structure, but a compound distinct from OA, DTX1, DTX2, or any esterified derivatives thereof (Table 1).

\subsection{Bioactivity-Guided Fractionation}

To first test the utility of the bioactivity-guided fractionation procedure, $500 \mu \mathrm{L}$ of hydrolyzed extract of clam (Mercenaria mercenaria) homogenate that had previously been spiked with $0.16 \mathrm{ppm}$ each of OA, DTX1, and DTX2 was fractionated and screened for PPIA activity. Three fractions were found to contain DST-like activity: the fractions collected from 23-24 $\mathrm{min}, 24-25 \mathrm{~min}$, and 26-27 min. Subsequent testing of these fractions by LC-MS/MS confirmed them as containing OA, DTX2, and DTX1, respectively (Figure $3 \mathrm{~A}$ ). Next, $500 \mu \mathrm{L}$ of hydrolyzed mussel extract that showed the highest PPIA activity from the initial set of 10 samples supplied by ME Department of Marine Resources (DMR) (Sample 2 from Table 1, >0.35 ppm OA eq. activity using the PPIA kit and 0.67 ppm OA eq. using the MaxSignal quantitative ELISA) was also fractionated. PPIA testing showed a prominent peak in bioactivity in the 26-27 min fraction, which was closest in elution order to DTX1 (Figure 3B). To determine the molecular ion of the compound responsible for the PPIA activity in fraction 26 of the mussel extract, full-scan experiments were performed by Q1 scanning in negative polarity (see Section 4.5.2). From an extracted ion chromatogram for $m / z$ 800-840, the expected mass range for DST-like compounds, an abundant peak was observed at a retention time of $7.3 \mathrm{~min}$, close to the known retention time of DTX1, using the chromatographic method described herein. The predominant ion observed in negative ionization mode for this chromatographic peak was $m / z$ 819.5, two Da larger than DTX1.

A product ion scan was then performed to obtain MS/MS fragmentation information for $\mathrm{m} / \mathrm{z} 819.5$ and to select product ions for SRM method development. The top three most abundant product ions were the same as those for known DSTs, $m / z 255.2,151.1$, and 131.1 (Figure S1). 

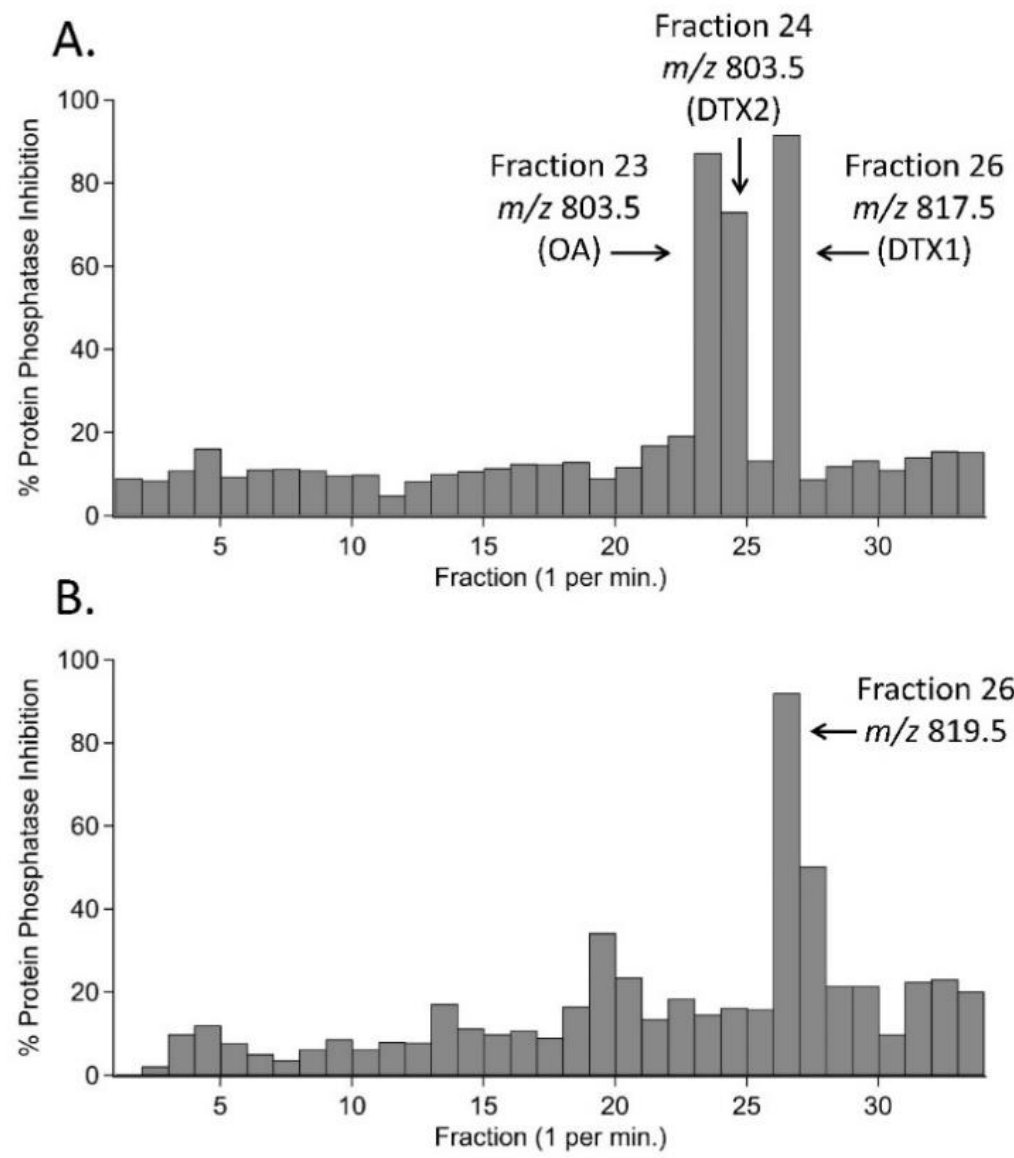

Figure 3. Results from the bioactivity-guided fractionation procedure for (A) control extract of clam (Mercenaria mercenaria) homogenate spiked with 0.16 ppm each of OA, DTX1, and DTX2, and (B) extract of mussel (Mytilus edulis) collected during 2016 Dinophysis norvegica bloom in the Gulf of Maine (corresponds to Sample 2 in Figure 1 and Table 1). LC-MS/MS confirmed OA, DTX2, and DTX1 in the spiked control sample, and the tentative toxin at $(\mathrm{M}-\mathrm{H})^{-} \mathrm{m} / \mathrm{z} 819.5$ in the mussel extract.

2.3. Liquid Chromatography-High Resolution Mass Spectrometry (LC-HRMS) Measurements of the PPIA Active Fraction

A peak detected in the 26-27 min fraction showed a measured accurate mass of $\mathrm{m} / \mathrm{z} 819.4908$, which corresponds to the $(\mathrm{M}-\mathrm{H})^{-}$of $\mathrm{C}_{45} \mathrm{H}_{71} \mathrm{O}_{13}(\Delta \mathrm{m}=0.9376 \mathrm{ppm})$. This compound differed from the measured accurate mass for a DTX1 standard of $m / z 817.4753\left(\Delta \mathrm{m}=1.1020 \mathrm{ppm}\right.$ for $\left.\mathrm{C}_{45} \mathrm{H}_{69} \mathrm{O}_{13}\right)$ by the addition of two hydrogen atoms, suggesting it was a dihydro derivative of DTX1. Furthermore, the LC-high-resolution MS/MS spectrum of this compound showed several product ions that were also consistent with the MS/MS spectrum of the DTX1 standard. These product ions were $m / z 255.1240$ as the most abundant ion, followed by $\mathrm{m} / \mathrm{z} 113.0609$ and $\mathrm{m} / \mathrm{z}$ 151.0766. The corresponding product ions in the DTX1 standard were $\mathrm{m} / \mathrm{z} 255.1242, \mathrm{~m} / \mathrm{z} 113.0610$, and $\mathrm{m} / \mathrm{z} 151.0766$. An additional product ion observed for the tentative dihydro-DTX1 was $\mathrm{m} / z$ 565.3014, corresponding to the chemical formula $\mathrm{C}_{30} \mathrm{H}_{45} \mathrm{O}_{10}(\Delta \mathrm{m}=-0.7591 \mathrm{ppm})$, and is 2 mass units higher than the corresponding product ion $(\mathrm{m} / \mathrm{z}$ $563.2861 ; \mathrm{C}_{30} \mathrm{H}_{43} \mathrm{O}_{10}, \Delta \mathrm{m}=-0.1296 \mathrm{ppm}$ ) for DTX1, indicating that the two additional hydrogen atoms are contained in this segment of the molecule (Figure 4). Specifically, the double bond at C14,15 is potentially modified on the tentative dihydro-DTX1. 
A.

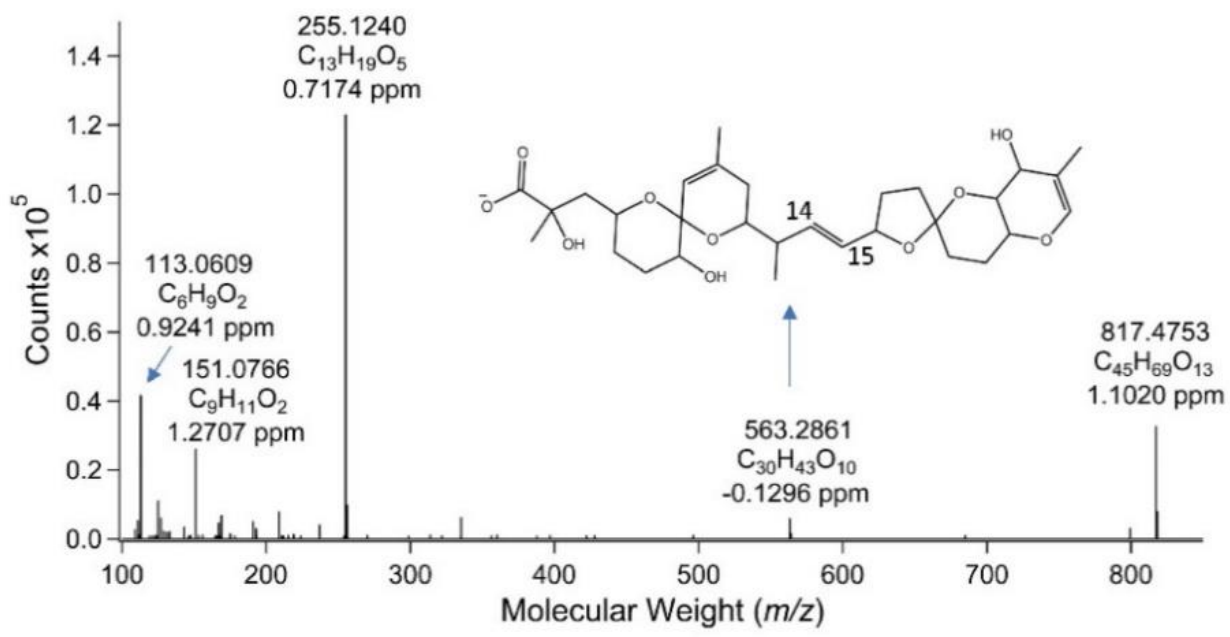

B.

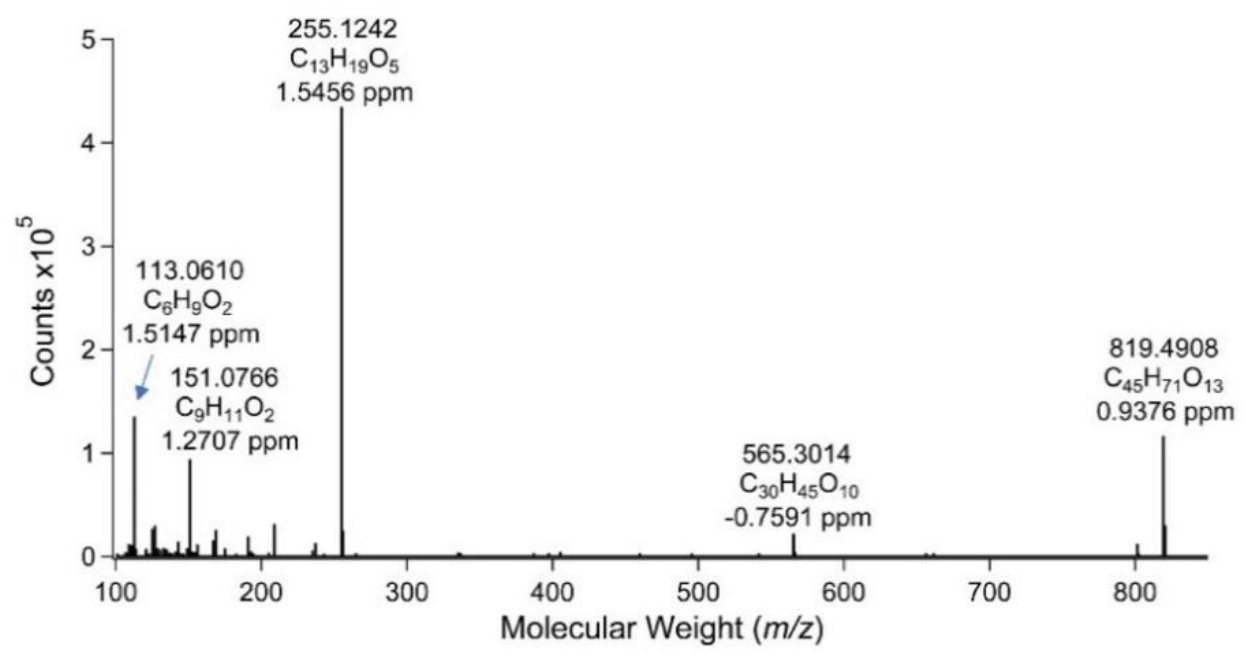

Figure 4. MS/MS spectra of (A) DTX1 certified reference material at (M-H) ${ }^{-} m / z 817.5$ and (B) suspect DST at $(\mathrm{M}-\mathrm{H})^{-} \mathrm{m} / \mathrm{z} 819.5$ from the 26-27-minute fraction from the PPIA bioactivity-guided fractionation procedure (depicted in Figure 3) for Sample 2 from Figure 1 and Table 1. Structure in panel A depicts $(\mathrm{M}-\mathrm{H})^{-} \mathrm{m} / \mathrm{z} 563.2861$ product ion showing the location of the 14-15 double bond. Structure of corresponding product ion in panel B with $(\mathrm{M}-\mathrm{H})^{-} \mathrm{m} / \mathrm{z} 565.3014$, from compound tentatively identified as dihydro-DTX1, has yet to be confirmed. Full structures of OA, DTX1, and DTX2, as well as proposed structures for the 255.2, 151.1, and 113.1 product ions used in the SRM analysis, are provided in Figure S2.

2.4. Selected Reaction Monitoring (SRM) Analysis for DSP Toxins and Dihydro-DTX1 in Water and Shellfish Samples and Comparison with PPIA

Using the data acquired from the previous analyses, minor modifications were made to the NSSP-approved LC-MS/MS method for the analysis of total (free plus esterified) DSP toxins in shellfish to include the preliminary detection of dihydro-DTX1 (detailed in Section 4.5.4 below). Using the modified LC-MS/MS method with data acquired in SRM scan mode, samples collected from the Gulf of Maine in 2016 and 2018 during blooms of D. norvegica were analyzed for the presence of these four compounds, and dihydro-DTX1 was confirmed to be the only DST present in shellfish as well as water (Figure 5). 

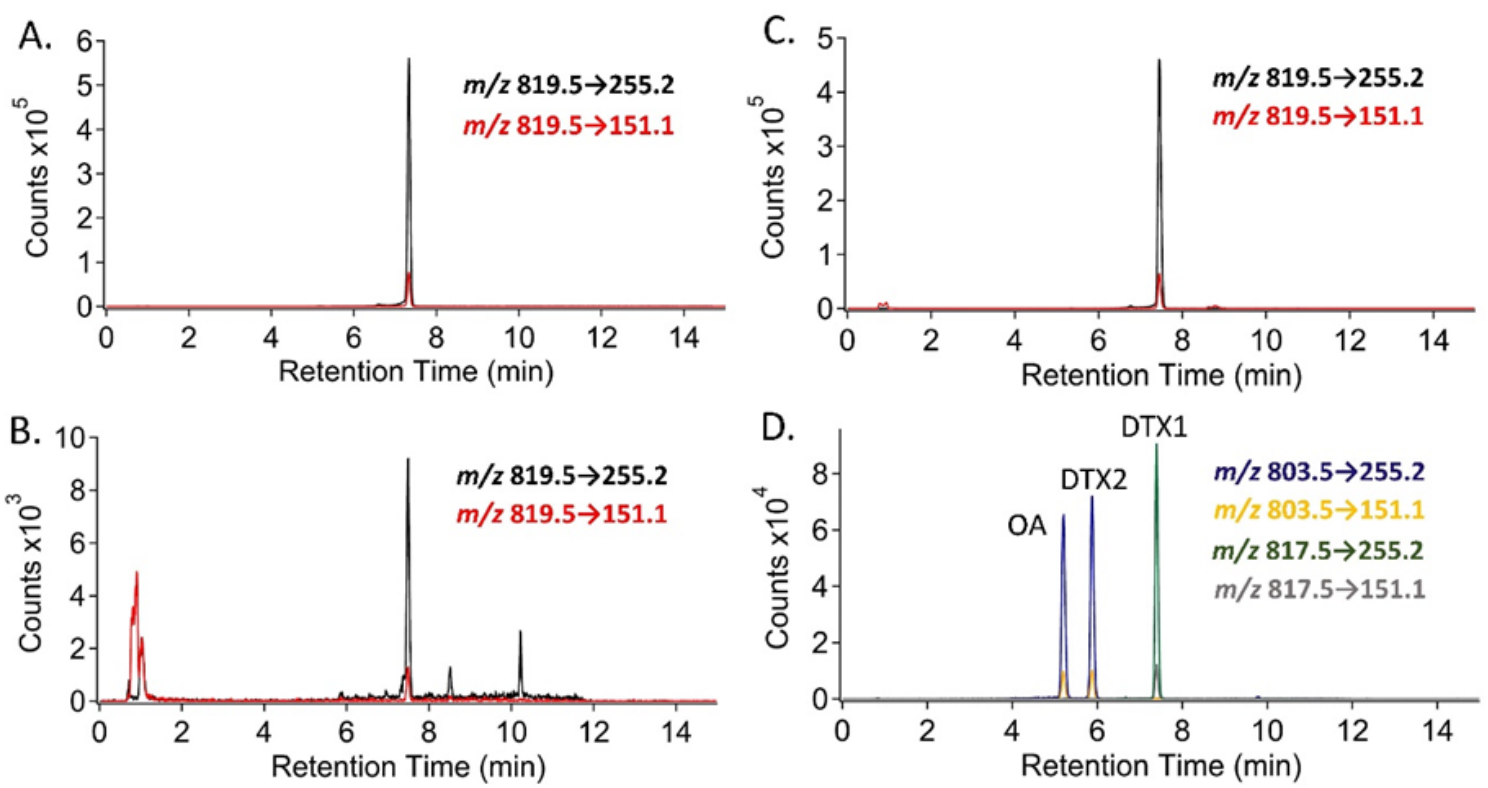

Figure 5. Extracted ion chromatograms from LC-MS/MS SRM analysis for dihydro-DTX1 ((M-H $)^{-} \mathrm{m} / \mathrm{z}$ 819.5), fragmenting to $m / z 255.2$ (for quantitation) (black trace) and 151.1 (for confirmation) (red trace), for (A) 26-27 min fraction from bioactivity guided fractionation procedure on mussel (M. edulis) extract from 2016 D. norvegica bloom in the Gulf of Maine, (B) filtered water sample collected during 2018 D. norvegica bloom in the Gulf of Maine, and (C) representative mussel (M. edulis) sample collected during 2018 D. norvegica bloom in the Gulf of Maine. OA ((M-H)- $m / z$ 803.5), DTX1 ((M-H)- $m / z$ 817.5), and DTX2 ((M-H) ${ }^{-} \mathrm{m} / \mathrm{z}$ 803.5), all fragmenting to $\mathrm{m} / \mathrm{z} 255.2$ and 151.1, were monitored for and were not detected (not shown). Panel (D) shows extracted ion chromatograms for a $12.8 \mathrm{ng} / \mathrm{mL}$ standard mix of OA, DTX1, and DTX2 run in the same analytical batch as panel $\mathrm{C}$ for comparison of relative retention times using the current chromatography for the approved LC-MS/MS method.

Next, the original 10 shellfish samples analyzed by multiple labs in 2016 were re-analyzed using the modified LC-MS/MS method and samples 1-8, collected during the 2016 D. norvegica bloom, were all confirmed to contain dihydro-DTX1 at concentrations that matched well with previous results generated by PPIA and ELISA (Table 1). In addition, shellfish samples from multiple species, including mussels (Mytilus edulis), oysters (Crassostrea virginica), and clams (Spisula solidissima and Mya arenaria), collected in 2016 and 2018 ( $\mathrm{N}=48$ total) were analyzed both by PPIA and by the modified LC-MS/MS method and results were compared using linear regression and correlation analyses for any sample >LOD of the PPIA kit $(\mathrm{N}=42)$. In the absence of an analytical standard for dihydro-DTX1, a DTX1 standard was used for external calibration, assuming an equivalent molar response [8]. The linear regression analysis found a slope of $1.13 \pm 0.07$, with an $\mathrm{r}^{2}$ of 0.86 . Correlation analysis of results from these same samples found the two analyses to be significantly correlated $(p<0.0001)$ with a Pearson $r$ score of 0.9260 (Figure 6).

Lastly, in order to test for species-specific differences in the bioaccumulation of dihydro-DTX1 in various commercial shellfish species from the Gulf of Maine, three species of shellfish: mussels (M. edulis), clams (S. solidissima), and oysters (C. virginica), were collected approximately weekly between May 30th and June 18th from a single location (Blue Hill Falls, symbol $(\triangle)$ from Figure 1 ) during the 2018 D. norvegica bloom and analyzed by LC-MS/MS. All three species were found to bioaccumulate dihydro-DTX1 with the rank order mussels $>$ clams $>$ oysters. Even though clams and oysters were found to accumulate less toxin overall compared to mussels, all three species would have exceeded regulatory guidance levels on at least one occasion during the course of the bloom, assuming equivalent potency and molar response to DTX1 (Figure 7). 


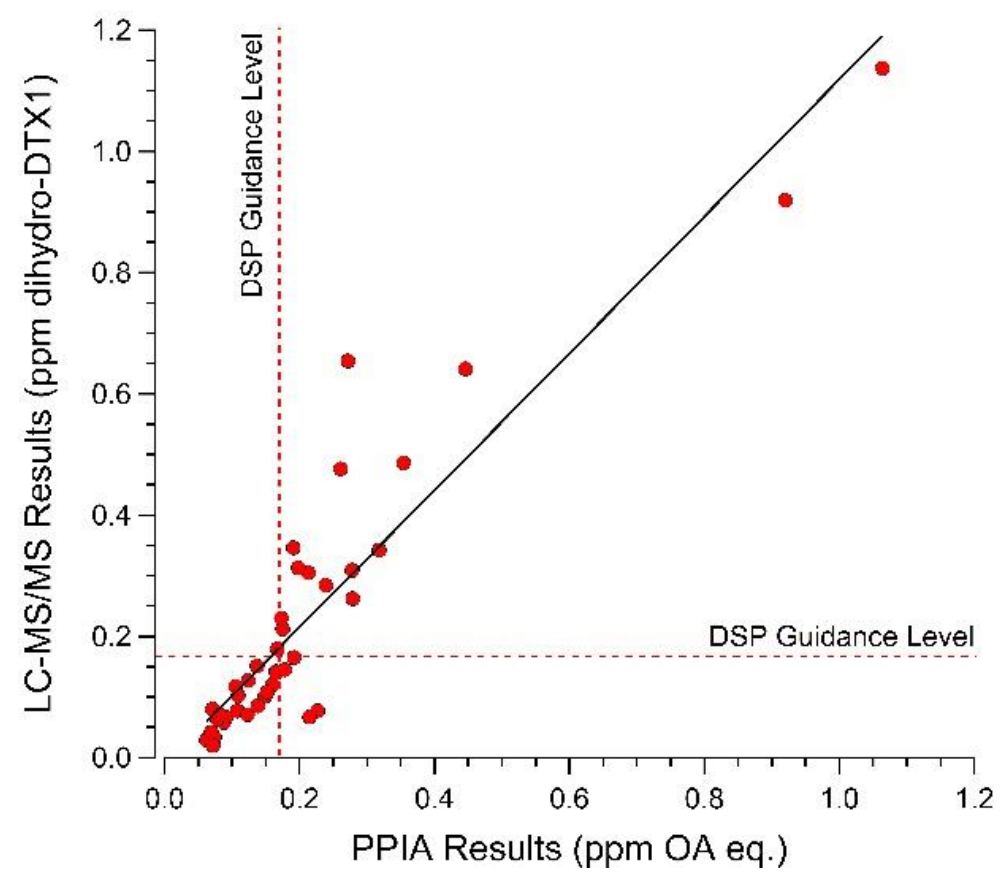

Figure 6. Comparison of protein phosphatase inhibition, as measured using a commercial PPIA kit, and dihydro-DTX1 concentration, as measured by LC-MS/MS SRM analysis, for mussels (Mytilus edulis), oysters (Crassostrea virginica), and clams (Spisula solidissima, and Mya arenaria) ( $\mathrm{N}=42$ total) collected in 2016 and 2018 from the central coast of the Gulf of Maine during blooms of Dinophysis norvegica. Dashed line indicates DSP guidance level of $0.16 \mathrm{ppm}$ OA eq. Solid line indicates best fit linear regression for the two data sets (slope $1.13 \pm 0.07, \mathrm{r}^{2} 0.86$ ).

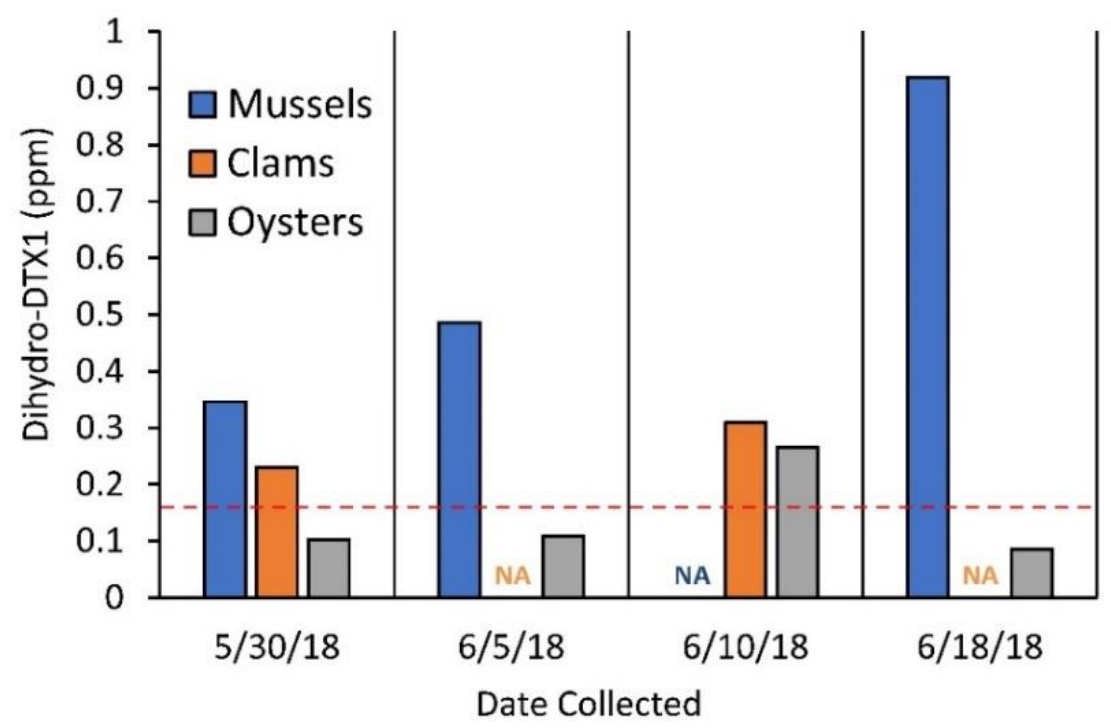

Figure 7. Dihydro-DTX1 accumulation in mussels (Mytilus edulis), clams (Spisula solidissima), and oysters (Crassostrea virginica) collected between May 30th and June 18th from Blue Hill Falls, Maine during the 2018 Gulf of Maine Dinophysis norvegica bloom. Each bar represents a single composite shellfish sample ( $\geq 12$ individuals each). Dashed line indicates DSP guidance level of 0.16 ppm OA eq. 


\subsection{Production of Dihydro-DTX1 in a Culture of Gulf of Maine D. norvegica}

Isolates of D. norvegica from the Gulf of Maine contained dihydro-DTX1 and pectenotoxin 2 (PTX2) in both the intracellular and extracellular fractions of the cultures (Table 2). OA, DTX1, and DTX2 were not detected in the extracts of $D$. norvegica cultures.

Table 2. Concentrations of dihydro-DTX1 and PTX2 in methanolic extracts from the intracellular and extracellular fractions of two cultures of D. norvegica isolated from the Gulf of Maine in 2018, as measured by LC-MS/MS. OA, DTX1, and DTX2 were also analyzed, but were not detected.

\begin{tabular}{|c|c|c|c|c|c|c|c|c|}
\hline \multirow{3}{*}{ Isolate } & \multicolumn{6}{|c|}{ dihydro-DTX1 (ppb) } & \multicolumn{2}{|c|}{ PTX2 (ppb) } \\
\hline & \multicolumn{3}{|c|}{ Intracellular } & \multicolumn{3}{|c|}{ Extracellular } & \multirow{2}{*}{ Intracellular } & \multirow{2}{*}{ Extracellular } \\
\hline & Free & Esterified & Total & Free & Esterified & Total & & \\
\hline$D N B H-F B 4$ & 1 & 60.6 & 61.5 & 1.3 & 5.3 & 6.5 & 36.3 & 3.9 \\
\hline$D N B H-B 3 F$ & 0.5 & 43.1 & 43.6 & 1.4 & 7.1 & 8.5 & 26.5 & 2.5 \\
\hline
\end{tabular}

Once subjected to alkaline hydrolysis, the toxin concentrations of dihydro-DTX1 in the intracellular fraction increased 60-80 fold, indicating the extensive presence of esterified toxin derivatives (Table 2). More specifically, the esterified toxins made up $98 \%$ of the total intracellular dihydro-DTX1 pool (free + esterified dihydro-DTX1) in both isolates. Extracellular dihydro-DTX1 derivatives were also present in the medium and dominated over the parent toxin with $80-83 \%$ present as esterified toxins. Overall, the amount of the parent congener, dihydro-DTX1, was similar inside and outside the cells; however, once esterified dihydro-DTX1 toxins were included in the analysis, significantly more toxin was located within the cells.

\section{Discussion}

Multiple cases of severe vomiting and diarrhea associated with the consumption of mussels and scallops, with a failure to detect any known pathogenic microorganisms, occurring in Japan in 1976-1977 led to the first description of the syndrome known as Diarrhetic Shellfish Poisoning (DSP) [9]. The source organism for this toxic syndrome, in Japan, was determined to be the dinoflagellate Dinophysis fortii and the unknown toxin was named dinophysistoxin [10]. Structural elucidation of this toxin, termed dinophysistoxin-1 (DTX1), determined it to be a novel polyether derivative of a C38 fatty acid that was closely related to the similar toxins okadaic acid (35-desmethyl-DTX1) and acanthifolicin (9,10-episulfide-35-desmethyl-DTX1) that had previously been identified during bioassay-guided searches for novel antitumor agents from marine sponges [11-13]. OA was later determined to also be produced by dinoflagellates, such as Prorocentrum lima and D. acuminata and to be the primary DSP toxin found in shellfish in Europe [14-16]. Another dinophysistoxin (DTX2, 31-desmethyl-35-methyl-OA) was later found in shellfish from Ireland [17]. To date, these three toxins, along with their 7-O-acyl shellfish-derived metabolites, have been the primary toxins found in shellfish associated with DSP events worldwide.

Since the original descriptions of OA, DTX1, and DTX2, a limited number of additional DST-derivatives have been described, although they have never been found to be present in shellfish in sufficient quantities to cause DSP. 2-Deoxy-OA and 7-deoxy-OA were both isolated as minor constituents from the dinoflagellate P. lima [18,19], 19-epi-OA was isolated as a minor constituent from P. belezianum [20], 19-epi-DTX1 and 19-epi-DTX2 were identified as minor impurities during the production of DSP-certified reference materials [21], while 14,15-dihydro-OA was isolated as a minor constituent from the marine sponge Halichondria okadai during the original isolation of OA [22]. Using a similar bioassay-guided isolation approach as was used to first identify OA from $H$. okadai, with the goal of identifying novel biologically active compounds from marine organisms, 14,15-dihydrodinophysistoxin-1, along with roughly equivalent amounts of OA and DTX1, was isolated from marine sponges (Phakellia sp.) collected in waters from the central coast of Maine in 1985 
and 1986 [18,23]. Although this compound was first reported over 20 years ago, its biological source was never determined, and it has not appeared in the scientific literature again to date.

The first record of D. norvegica blooming in North America occurred in Bedford Basin, Nova Scotia on the Atlantic coast of Canada in 1990 [24]. Maximum cell densities were $4.5 \times 10^{5}$ cells L $^{-1}$ and DST(s) were reported to be present both in net tow plankton samples as well as in experimentally exposed scallops (Placopecten magellanicus) based on a commercial ELISA. In that same year, the first cases of DSP were reported in North America from mussels harvested from Mahone Bay, Nova Scotia, Canada $[25,26]$. During that event, D. norvegica was reported in plankton samples collected from Mahone Bay, but no DSP toxins were detected [25] (methods not described). Shellfish from the DSP event were positive for DST-like activity by mouse bioassay and DTX1 was confirmed by a combination of methods including LC-MS and proton NMR spectroscopy [26]. P. lima, cultured from water samples collected during the same time period, was subsequently shown to produce both OA and DTX1 and the event was attributed to P. lima [25]. At that time, the methods required to culture Dinophysis spp. had not yet been established, so the contribution of Dinophysis to this DSP event could not be determined.

Not long after the first DSP event in eastern Canada, several unexplained incidents of shellfish-related gastroenteritis in Maine, USA prompted a study to assess the prevalence of potential DST-producing organisms and the occurrence of DST-like toxicity in mussels along the entire state coast [27]. In that study, DST-like activity in mussel hepatopancreas was detected using a PPIA test only in the central coastal region in the vicinity of Eastern Bay and Frenchman Bay, the same region as our current study. The most prevalent potentially DST-producing species found in this region at the time was $D$. norvegica, but analysis of net tow samples were negative for protein phosphatase inhibitory (PPI) activity. Both mussels and plankton were also negative for OA and DTX1 by LC-MS/MS testing, but the authors noted that the bioactivity detected in mussels by PPIA was likely below the detection limit for LC-MS/MS. Although lower in number, P. lima was documented in the epiphytic community and testing of a concentrated sample of this material detected DST-like activity using the PPIA test with the presence of DTX1 confirmed by LC-MS/MS; therefore, the authors concluded that P. lima was the source of the PPI activity in mussels during that study. Follow-on studies performed between 2001 and 2003 looking at the seasonal distribution of potential DST-producing dinoflagellates and DSP-like bioactivity in plankton and shellfish in several northeastern states found a weak but significant correlation between PPI activity and the presence of P. lima in the epibiota [28,29]. The authors also noted the presence of both D. acuminata and D. norvegica throughout the study region, with D. norvegica being the more prevalent of the two species in the coastal Gulf of Maine, but found PPI activity associated with a bloom of D. norvegica only once [29]. Overall, toxins in shellfish were found only rarely and only at low levels and therefore the authors concluded that the threat of DSP in the region was minimal despite the presence of several potential DSP-producing species [29].

We show here that $D$. norvegica in the central coast of the Gulf of Maine, both in culture and in-situ, produces a DST-like toxin distinct from OA, DTX1, or DTX2, the only DSTs associated with DSP worldwide to date. The toxin has been tentatively identified as a dihydro-derivative of DTX1 and is likely 14,15 dihydro-DTX1 as was described from marine sponges collected from this same region over 30 years ago, although confirmation of this will require further structural elucidation studies. The presence of this toxin, as quantified against a DTX1 standard by LC-MS/MS analysis, the current reference method for DST testing under the National Shellfish Sanitation Program in the US [30], correlated well with PPIA testing, indicating that this toxin alone can explain the DST-like activity detected in this region in association with blooms of D. norvegica in 2016 and 2018. This also suggests that dihydro-DTX1 binds equivalently to the PP2A enzyme used in the commercial PPIA kit compared to OA, the standard utilized in the kit. During the original description of 14,15-dihydro-DTX1, this compound was reported to be equally potent as compared to OA and DTX1 using a cytotoxicity assay against L-1210 leukemia cells [23], but in other studies looking at the relative inhibitory potencies of various OA-derivatives, including 14,15-dihydro-OA, this compound was reported to have a higher 
dissociation constant (lower affinity) for both PP1 and PP2A, isolated from rabbit skeletal muscle, compared to OA and DTX1 [22]. This was proposed to be due to the conversion of the double bond between C-14 and C-15 to a single bond, which the authors hypothesized to stabilize the circular confirmation known to be important for the binding of these compounds to protein phosphatases [22]. Determination of the relative potency of the dihydro-DTX1 produced by D. norvegica compared to the other known DSP-causing DSTs will require further testing once a better characterized, analytically pure preparation of this compound is available. In the meantime, it appears that PPIA screening with confirmatory LC-MS/MS testing utilizing $m / z 819.5$ with product ions at $m / z 255.2$, for quantitation, and 151.1 and/or 113.1 for confirmation, in negative ion mode with acidic chromatography according to the current NSSP method is a viable means of screening for this toxin in shellfish until a formal analyte extension study can be performed. As with all marine biotoxins, chemical analytical methods such as HPLC or LC-MS/MS depend greatly on the availability of accurate toxicity equivalency factors (TEFs) [31]. The determination of a TEF for the dihydro-DTX1 compound is a priority so that the risk this toxin poses to human consumers can be properly assessed, especially considering that this toxin has not been conclusively linked to any DSP-like illnesses to date. This work is currently in progress.

The central coast of the Gulf of Maine is not the only region in the US where D. norvegica occurs, although it does appear to be the only region in the US that we are aware of where it is the predominant species of Dinophysis present. D. norvegica has been documented in lower abundance compared to species such as D. acuminata in the mid-Atlantic region [7], the Pacific Northwest [4], and along the central coast of California [32]. Historically, D. norvegica was shown to reach high abundances on the Atlantic coast of Canada, particularly Nova Scotia [24], and still occurs occasionally in high abundance along with D. acuminata in that region today (Nancy Lewis, personal communication). Worldwide, D. norvegica occurs in many cold-water coastal environments, such as Norway, where it commonly co-occurs with other Dinophysis species such as D. acuta and D. acuminata [33], and the Baltic Sea [34], but it is often considered a minor contributor to DSP events [35,36]. Studies looking at toxins in pooled cells of D. norvegica picked from environmental samples in Norway [37] and Japan [38] found PTX in 10/10 samples, but found low levels of OA, as measured by targeted LC-MS/MS, in only 1/10 samples, with no DTX1 or DTX2 detected. It remains to be determined if D. norvegica in any of these additional locations also produces the dihydro-DTX1 compound and what potential risk this poses to shellfish consumers.

\section{Materials and Methods}

\subsection{Phytoplankton and Shellfish Sampling}

Individual phytoplankton samples were each comprised of 10 liters of surface seawater collected from shore and gravity filtered through a $20 \mu \mathrm{m}$ sieve. Once the seawater had fully drained, the cylinder was inverted and placed onto a funnel attached to a $50 \mathrm{~mL}$ centrifuge tube. Phytoplankton collected on the sieve were rinsed into the collection tube using freshly filtered seawater. Sample tubes were suspended by a rack in a cooler held between $0-10{ }^{\circ} \mathrm{C}$ during transport. Once transported to the lab, samples were held at $0-4{ }^{\circ} \mathrm{C}$ and analyzed within $24 \mathrm{~h}$. If samples could not be analyzed within this timeframe, they were fixed with $80 \mu \mathrm{L}$ of Lugol's iodine and stored at $0-4{ }^{\circ} \mathrm{C}$ until analysis.

Swift M10 compound microscopes (Swift Optical Instruments, Schertz, TX, USA) were used at 100X magnification for phytoplankton enumeration. Each sample tube was gently inverted three times and $1 \mathrm{~mL}$ of the sample aliquoted onto a Sedgwick Rafter gridded slide for enumeration. Using light microscopy, $0.2 \mathrm{~mL}$ (200 grids) were analyzed, after which the sample was discarded, the slide rinsed with deionized water, and a second sample was loaded and analyzed. The genus Dinophysis was enumerated using morphological characteristics. The total counts of individual cells in the two separate aliquots were averaged with numbers reported in cells liter ${ }^{-1}$.

Each bivalve sample was comprised of 12-15 specimens for a given species that were composited for analysis. Samples were transported live in a cooler held at a temperature of $0-10{ }^{\circ} \mathrm{C}$. Upon delivery 
to the lab, samples were stored at $0-4{ }^{\circ} \mathrm{C}$ and were processed within $24 \mathrm{~h}$ of collection. For processing, each sample was rinsed, drained, shucked, and the tissues were homogenized by a blender. Homogenized samples were stored at $0-4{ }^{\circ} \mathrm{C}$ and extracted within $24 \mathrm{~h}$. Samples not scheduled for analysis within $24 \mathrm{~h}$ were frozen at $-20^{\circ} \mathrm{C}$ until extraction. Remaining homogenates were stored at $-20^{\circ} \mathrm{C}$ and after 2 months, archived in long-term storage at $-80^{\circ} \mathrm{C}$. Additional aliquots for further chemical analysis as part of this study were taken from these archived samples.

\subsection{Standards and Reagents}

Certified reference materials (CRMs) for OA, DTX1, and DTX2 were purchased from the National Research Council Canada (Halifax, NS, Canada). All reagents were purchased from Sigma-Aldrich (St. Louis, MO, USA) and were of analytical grade or better. All solvents were purchased from Fisher Scientific (Pittsburgh, PA, USA) and were LC-MS grade.

\subsection{Commercial Test Kits}

Three commercial test kits for the determination of DSP toxins in shellfish were utilized in the study: 1. Okadaic Acid (DSP) PP2A kit (PN 520025, Abraxis, Inc. Warminster, PA, USA), 2. Reveal 2.0 for DSP (NEOGEN Corporation, Lansing, MI, USA), and 3. MaxSignal Okadaic Acid (DSP) ELISA Test Kit (Bioo Scientific Corp, Austin, TX, USA). The Okadaic Acid (DSP) PP2A kit is an in-vitro test based on the inhibition of protein phosphatase 2A, a known biological target for DSTs. The Reveal 2.0 for DSP kit is a qualitative antibody-based lateral flow test, while the MaxSignal Okadaic Acid (DSP) ELISA kit is a quantitative micro-well plate antibody-based test. For all kits, the manufacturer's instructions were followed, with the exception of the Okadaic Acid (DSP) PP2A kit where $2 \mathrm{~g}$ of shellfish homogenate was extracted in a total of $20 \mathrm{~mL}$ solvent (1:10 dilution) as opposed to the current manufacturer's instructions of $5 \mathrm{~g}$ homogenate extracted in $25 \mathrm{~mL}$ solvent (1:5 dilution). To compensate for the different extraction dilutions, the total volume of the dilution in buffer after sample hydrolysis was changed from $20 \mathrm{~mL}$ to $10 \mathrm{~mL}$ (Section D, Step 12 of manufacturer's instructions). This adjustment corresponds to the standard extraction for the validated LC-MS/MS method for DSTs and allows the same extract to be used for both analyses.

\subsection{Bioactivity-Guided Fractionation}

Purification of DSP-like compound(s) from Maine shellfish was achieved through bioactivity guided fractionation following a modification of the method described in [39]. First, a homogenized composite sample of 12 mussels (Mytilus edulis), collected in 2016 from the Gulf of Maine during the $D$. norvegica bloom and previously shown to contain $>0.35 \mathrm{ppm}$ OA equivalent activity using the PPIA kit and 0.67 ppm OA eq. using the MaxSignal quantitative ELISA, both described in the "Commercial Test Kit" section above, was extracted following the standard procedure used in the LC-MS/MS analysis described below ( $2 \mathrm{~g}$ homogenate extracted twice with $9 \mathrm{~mL}$ each of $\mathrm{MeOH}$ with the final volume adjusted with $\mathrm{MeOH}$ to $20 \mathrm{~mL}$ ). A $2 \mathrm{~mL}$ sub-sample was hydrolyzed with $250 \mu \mathrm{L}$ of $2.5 \mathrm{M} \mathrm{NaOH}$ followed by heating in a water bath at $76^{\circ} \mathrm{C}$ for $40 \mathrm{~min}$. After cooling to room temperature, the sample was neutralized with $250 \mu \mathrm{L}$ of $2.5 \mathrm{M} \mathrm{HCl}$. A sub-sample of hydrolyzed extract $(500 \mu \mathrm{L})$ was injected onto an Agilent 1200 Series HPLC system equipped with a G1363A $900 \mu \mathrm{L}$ extended loop injection kit and a 1260 Series model G1364C fraction collector (Agilent Technologies, Waldbronn Germany). Separations were achieved using a $4.6 \times 150 \mathrm{~mm}, 5 \mu \mathrm{m}$ particle size, Zorbax Eclipse XDB-C18 column (Agilent Technologies, Waldbronn Germany) at a flow rate of $500 \mu \mathrm{L} / \mathrm{min}$ using the following elution profile: $70 \%$ A:30\% B hold for $2 \mathrm{~min}$, increasing linearly to $100 \% \mathrm{~B}$ over $20 \mathrm{~min}$, hold at $100 \% \mathrm{~B}$ for $5 \mathrm{~min}$, decrease to $70 \% \mathrm{~A}: 30 \%$ B over $3 \mathrm{~min}$, hold at $70 \% \mathrm{~A}: 30 \% \mathrm{~B}$ for $5 \mathrm{~min}$. Mobile phase A consisted of $100 \%$ water with $0.1 \%$ TFA and mobile phase B consisted of $100 \%$ acetonitrile with $0.1 \%$ TFA following [39]. Fractions were collected every minute over the entire 35 min run time. All fractions were tested for protein phosphatase inhibitory activity using the commercial kit described in Section 4.3. As a positive control, a homogenate of clam (Mercenaria mercenaria), previously shown 
to be $<$ LOD for DSP toxins by LC-MS/MS, was spiked with $0.16 \mathrm{ppm}$ each of methanolic reference solutions of OA, DTX1, and DTX2, then extracted, fractionated, and analyzed for PPIA activity as described above.

\subsection{Liquid Chromatography-Mass Spectrometry}

4.5.1. Lipophilic Toxin Screening by Liquid Chromatography-High Resolution Mass Spectrometry (LC-HRMS) Analysis

Initial lipophilic toxin screening using LC-HRMS analyses, performed at NRC Canada, of the first set of 10 samples collected by ME DMR in 2016 for DSTs as well as azaspiracids, pectenotoxins, and yessotoxins was performed according to [40] and [41].

\subsubsection{Q1 Scanning and MS/MS Analysis of the Unknown DST-Like Compound}

Initial LC-MS experiments on the semi-purified extract from the 26-27 min fraction obtained from the PPIA bioactivity-guided fractionation of Sample 2 (from Figure 1 and Table 1) were performed using an Acquity Ultra-Performance Liquid Chromatography system (Waters Corporation, Manchester, UK) coupled to a Sciex QTrap 5500 mass spectrometer equipped with a Turbo V ionization source (SCIEX, Framingham, MA, USA). The column used for separations was a Waters BEH C18 $(1.7 \mu \mathrm{m}$, $1.0 \mathrm{~mm} \times 150 \mathrm{~mm}$ ) (Waters Corp., Milford, MA). The aqueous mobile phase (A) consisted of $2 \mathrm{mM}$ ammonium formate and $50 \mathrm{mM}$ formic acid in water. The organic mobile phase (B) consisted of $2 \mathrm{mM}$ ammonium formate and $50 \mathrm{mM}$ formic acid in $95 \%$ acetonitrile/5\% water. For initial method development studies, gradient conditions started at $50 \% \mathrm{~B}$, were maintained for two min at $50 \% \mathrm{~B}$, and were then linearly increased to $70 \% \mathrm{~B}$ in four min, followed by $100 \% \mathrm{~B}$ in two min, held at $100 \% \mathrm{~B}$ for five min, then decreased to $50 \% \mathrm{~B}$ in $0.5 \mathrm{~min}$ and lastly, were held at $50 \% \mathrm{~B}$ for $4.5 \mathrm{~min}$. The total run time was $18 \mathrm{~min}$ at a flow rate of $0.12 \mathrm{~mL} / \mathrm{min}$. The column temperature was maintained at $40^{\circ} \mathrm{C}$ while the autosampler temperature was $10^{\circ} \mathrm{C}$. The injection volume was $5 \mu \mathrm{L}$.

The electrospray ionization (ESI) source parameters were as follows: source temperature $550{ }^{\circ} \mathrm{C}$, ion spray voltage $-4500 \mathrm{~V}$, curtain gas 25 psi, gas 1 and 2 both 40 psi. Full scan, negative ionization mode data were collected using a mass range from 500 to $900 \mathrm{Da}$ and a scan rate of $200 \mathrm{Da} \mathrm{s}^{-1}$. Product ion scans for $\mathrm{m} / \mathrm{z} 819.50$ were collected using a mass range from 100 to $900 \mathrm{Da}$ and a scan rate of $1000 \mathrm{Da} \mathrm{s}^{-1}$. The declustering and entrance potentials were $-110 \mathrm{~V}$ and $-10 \mathrm{~V}$, respectively, and for product ion scans the collision energy was $-70 \mathrm{~V}$ and collision cell exit potential was $-15 \mathrm{~V}$.

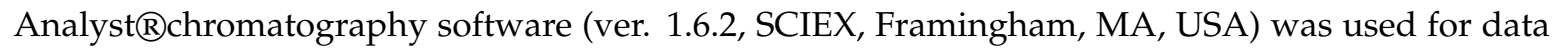
visualization and analysis.

\subsubsection{LC-HRMS Analysis of Dihydrodinophysistoxin-1}

LC-HRMS measurements of the semi-purified extract from the 26-27 min fraction of Sample 2 (from Figure 1 and Table 1) was performed using a Nexera LC system (Shimadzu, Columbia, MD, USA) coupled with a Q Exactive Hybrid Quadrupole-Orbitrap mass spectrometer (Thermo Scientific, Waltham, MA, USA). The column and mobile phases were the same as described in Section 4.5.2., with the LC run time shortened to $15 \mathrm{~min}$. Gradient conditions starting at $50 \%$ B were maintained for two min, then linearly increased to $70 \%$ B in four min, followed by $99 \%$ B in two min, held at $99 \%$ B for two $\mathrm{min}$, then decreased to $50 \% \mathrm{~B}$ in $0.5 \mathrm{~min}$ and held at this level for $4.5 \mathrm{~min}$ to re-equilibrate. All other chromatography and autosampler settings were the same as described in Section 4.5.2.

Analytes were ionized using ESI in negative mode with source conditions as follows: spray voltage $-3000 \mathrm{~V}$, capillary temperature $320^{\circ} \mathrm{C}$, sheath gas 5 arbitrary units (au), and aux gas 0 au. A targeted-single ion monitoring (SIM)/data dependent (dd)-MS ${ }^{2}$ experiment was performed on the sample. The instrument was set to monitor and perform MS/MS on $m / z$ 819.49002. The parameters for SIM were a mass resolution setting of 70,000, automatic gain control (AGC) of $2 \times 10^{5}$, maximum injection time of $200 \mathrm{~ms}$, and an isolation window of $2 \mathrm{~m} / \mathrm{z}$. The parameters for dd-MS ${ }^{2}$ were as follows: 
mass resolution setting of 35,000 , AGC $2 \times 10^{5}$, maximum injection time $100 \mathrm{~ms}$, normalized collision energy 35. The dd settings to initiate MS/MS was a minimum AGC of $8 \times 10^{3}$.

4.5.4. LC-MS/MS Selected Reaction Monitoring (SRM) Analysis for OA, DTX1, DTX2, and Dihydro-DTX1

LC-MS/MS testing by SRM was performed using an Acquity Ultra-Performance Liquid Chromatography system coupled to a Sciex QTrap 5500 mass spectrometer equipped with a Turbo V ionization source. The protocol "LC-MS/MS Method for the Detection of DSP Toxins in Shellfish" [42] that was adopted in 2017 by the Interstate Shellfish Sanitation Conference (ISSC) for use in the US National Shellfish Sanitation Program (NSSP) [30] was followed with minor modifications to include the measurement of dihydro-DTX1 as detailed below. All samples were subjected to alkaline hydrolysis, following the referenced protocol, to measure total (free plus esterified) toxins. The column, mobile phase, gradient conditions, and ESI source parameters were the same as those used for LC-HRMS measurements (Section 4.5.2) and in the ISSC protocol. Data acquisition was in negative ionization mode using SRM. The SRM parameters for dihydro-DTX1 were as follows: Q1 m/z 819.5, Q3 m/z 255.2 and 151.1, dwell time $100 \mathrm{~ms}$, declustering potential $-110 \mathrm{~V}$, entrance potential $-10 \mathrm{~V}$, collision energy $-70 \mathrm{~V}$, and collision cell exit potential $-15 \mathrm{~V}$. The peak area of the SRM transition $\mathrm{m} / z \mathrm{819.5} \rightarrow 255.2$ was used for quantitation, while the $m / z$ 819.5 $\rightarrow 151.1$ SRM transition was used for confirmation. In the absence of a standard, quantitation of dihydro-DTX1 was performed using the calibration curve of DTX1. Analyst $®$ chromatography software (ver. 1.6.2, SCIEX, Framingham, MA, USA) was used for peak area integration and quantitation.

\subsection{Analysis of Gulf of Maine Shellfish for Dihydro-DTX1 by LC-MS/MS SRM and Comparison with PPIA}

To compare the determination of dihydro-DTX1 by LC-MS/MS SRM (as described in Section 4.5.4) to PPIA (as described in Section 4.3), 48 shellfish samples collected by ME DMR during blooms of $D$. norvegica in 2016 and 2018, each comprising of $\geq 12$ composited individuals and representing mussels (Mytilus edulis), oysters (Crassostrea virginica), and clams (Spisula solidissima and Mya arenaria), were analyzed using both methods. For any samples found to be greater than the working range of the PPIA kit (>0.35 ppm OA eq.), samples were diluted using the kit-provided dilution buffer and re-analyzed. All samples $>$ LOD for the PPIA kit $(0.063 \mathrm{ppm})(\mathrm{N}=42)$ were compared to results determined by LC-MS/MS SRM, quantified using an external DTX1 standard curve, using both linear regression and correlation analysis with the program GraphPad Prism (ver. 5.01 for Windows, GraphPad Prism Software, San Diego, CA, USA).

During the 2018 D. norvegica bloom in the Gulf of Maine, three species of shellfish: mussels (Mytilus edulis), clams (Spisula solidissima), and oysters (Crassostrea virginica), were collected approximately weekly ( $\geq 12$ composited individuals per sample) between May 30th and June 18th from a single location (Blue Hill Falls, Figure 1) and analyzed by LC-MS/MS SRM (as described in Section 4.5.4) to look for species-specific differences in the accumulation of dihydro-DTX1.

\subsection{Testing of a Gulf of Maine Dinophysis norvegica Culture for DST Production}

Two new cultured clonal isolates of D. norvegica (DNBH-FB4 and DNBH-B3F) were established in culture in May 2018 from surface water collected from Blue Hill Falls, Maine, following the single-cell isolation methods described by [43]. At the time of water collection, the salinity was 30 psu and the water temperature was $12{ }^{\circ} \mathrm{C}$. During isolation and maintenance of the culture, D. norvegica were fed Mesodinium rubrum, which had been previously raised on Teleaulax amphioxeia isolated from Japan [44] following the protocols of [45] as modified by [46]. The dinoflagellate, ciliate, and cryptophyte cultures were grown in modified f/6-Si medium [47] and a salinity of 30 at $15^{\circ} \mathrm{C}$ in dim light $(40 \mu \mathrm{mol}$ photons-m-2·sec-1) under a $14 \mathrm{~h}: 10 \mathrm{~h}$ light:dark photocycle.

To assess the toxigenicity of DNBH-FB4 and DNBH-B3F, cells were inoculated into fresh medium, salinity $30 \mathrm{psu}$, at 400 cells. $\mathrm{mL}^{-1}$, fed M. rubrum at a 1:10 ratio of prey to predator, and monitored 
every 3 days for the complete consumption of $M$. rubrum by examining $1 \mathrm{~mL}$ subsamples in a Sedgewick-Rafter counting cell at 100x using an Olympus CX31 light microscope (Olympus America, Waltham, MA, USA). Three days after all ciliate prey were consumed, (i.e., during late exponential growth of the dinoflagellate) the culture was harvested for toxin analysis.

The harvested cultures were gently separated into cells (intracellular toxins) and medium (extracellular toxins) using a $10 \mu \mathrm{m}$ sieve and the components were extracted and analyzed for toxins separately. Cells and medium were bath-sonicated at room temperature for 15 min (Branson 5800 Ultrasonic Cleaner, 5800) and loaded onto an Oasis HLB 60 mg cartridge (Waters Corporation, Millford, MA, USA) that was previously equilibrated with $3 \mathrm{~mL}$ of $\mathrm{MeOH}$ and $3 \mathrm{~mL}$ of GenPure water. The cartridge was then washed with $6 \mathrm{~mL}$ of GenPure water, blown dry, and eluted with $1 \mathrm{~mL}$ of $100 \%$ $\mathrm{MeOH}$ into a glass $1.5 \mathrm{~mL}$ high recovery $\mathrm{LC}$ vial and stored at $-20^{\circ} \mathrm{C}$ until analyzed. A portion of the sample underwent alkaline hydrolysis to enable the quantitation of total DSP toxins (free plus esterified) following [48]. Extracts, original and alkaline hydrolyzed, were analyzed using an Acquity liquid chromatography system coupled with a Xevo mass spectrometer with electrospray ionization (Waters, Milford, MA, USA) following the DSP and PTX2 analytical methods described by [49].

Dihydro-DTX1 was detected using selected reaction monitoring (SRM) in negative ion mode with the transitions $m / z \quad 819.5 \rightarrow 255.1,819.5 \rightarrow 819.5,819.5 \rightarrow 151.1$, and $819.5 \rightarrow 113.1$. Quantitation was performed using the former SRM transition; concentrations were calculated using an external DTX1 standard curve with MassLynx 4.1 software (Waters Corporation, Millford, MA, USA). Matrix spikes, final concentration of $12.5 \mathrm{ppb}$ DTX1, were conducted to confirm separation from DTX1. Toxin data are presented as toxin concentration per $\mathrm{mL}$ of culture, and free vs. esterified, with the latter being calculated through the subtraction of free toxins from total toxins.

Supplementary Materials: The following are available online at http://www.mdpi.com/2072-6651/12/9/533/s1, Table S1: Sampling site coordinates for shellfish and phytoplankton samples collected during the 2016 Dinophysis norvegica bloom depicted in Figures 1 and 2. Figure S1: MS/MS spectrum of $m / z 819.5$ peak detected in the 26-27 min fraction from the bioactivity guided fractionation extract of mussel (Mytilus edulis) collected during 2016 Dinophysis norvegica bloom in the central coast of the Gulf of Maine, USA; Figure S2: Structure of precursor ions and proposed product ion structures for okadaic acid (OA), dinophysistoxin 1 (DTX1), and dinophysistoxin 2 (DTX2).

Author Contributions: Conceptualization, J.R.D., W.L.S., J.M., and J.L.S.; Investigation, J.R.D., W.L.S., M.D.C., J.M., A.E.H., J.L.S., D.M.K., P.M., C.D.R., C.A.B., and S.K.L.; Methodology, J.R.D., W.L.S., M.D.C., J.L.S., D.M.K., and P.M.; Resources, J.M., A.E.H., B.J.L., and D.W.M.; Supervision, K.K., S.D.A., J.B., and S.K.L.; Writing-original draft, J.R.D., W.L.S., M.D.C., A.E.H. and J.L.S.; Writing-review and editing, J.M., D.M.K., P.M., S.D.A., and S.K.L. All authors have read and agreed to the published version of the manuscript.

Funding: Partial support for this research was received from the National Oceanic and Atmospheric Administration, National Centers for Coastal Ocean Science Competitive Research, Ecology and Oceanography of Harmful Algal Blooms Program under awards NA17NOS4780184 and NA19NOS4780182 to Juliette Smith (VIMS) and Jonathan Deeds (US FDA), and Prevention, Control, and Mitigation of Harmful Algal Blooms program award NA17NOS4780179 to Stephen Archer. This paper is ECOHAB publication number EC0956.

Acknowledgments: The authors would like to express their gratitude to Marta Sanderson and Han Gao (VIMS) for their assistance in culture maintenance and toxin analysis, Satoshi Nagai (National Research Institute of Fisheries Science, Japan) for his sharing of Mesodinium rubrum and Teleaulax amphioxeia cultures, Stephen Conrad (CFSAN) for assistance with figure preparation, and Claude Mallet (Waters Inc.) and Sabrina Giddings (Biotoxin Metrology, NRC Canada) for their technical assistance.

Conflicts of Interest: The authors declare no conflict of interest

\section{References}

1. Campbell, L.; Olson, R.J.; Sosik, H.M.; Abraham, A.; Henrichs, D.W.; Hyatt, C.J.; Buskey, E.J. First harmful Dinophysis (Dinophyceae, Dinophysiales) bloom in the U.S. revealed by automated imaging flow cytometry. J. Phycol. 2010, 46, 66-75. [CrossRef]

2. Deeds, J.R.; Wiles, K.; Heideman, G.B., VI; White, K.D.; Abraham, A. First US report of shellfish harvesting closures due to confirmed okadaic acid in Texas Gulf coast oysters. Toxicon 2010, 55, 1138-1146. [CrossRef]

3. Lloyd, J.K.; Duchin, J.S.; Borchert, J.; Flores Quintana, H.; Robertson, A. Diarrhetic shellfish poisoning, Washington, USA, 2011. Emerg. Infec. Dis. 2013, 19, 1314-1316. [CrossRef] 
4. Trainer, V.L.; Moore, L.; Bill, B.D.; Adams, N.G.; Harrington, N.; Borchert, J.; da Silva, D.A.M.; Eberhart, B.L. Diarrhetic shellfish toxins and other lipophilic toxins of human health concern in Washington State. Mar. Drugs. 2013, 11, 1815-1835. [CrossRef]

5. Tango, P.; Butler, W.; Lacouture, R.; Goshorn, D.; Magnien, R.; Michael, B.; Hall, S.; Browhawn, K.; Wittman, R.; Beatty, W. An unprecedented bloom of Dinophysis acuminata in Chesapeake Bay. In Harmful Algae 2002; Steidinger, K.A., Landsberg, J.H., Tomas, C.R., Vargo, G.A., Eds.; Florida Fish and Wildlife Conservation Commission, Florida Institute of Oceanography, and Intergovernmental Oceanographic Commission of UNESCO: St. Petersburg, FL, USA, 2004; pp. 358-360.

6. Hattenrath-Lehmann, T.K.; Marcoval, M.A.; Berry, D.L.; Fire, S.; Wang, Z.; Morton, S.L.; Gobler, C.J. The emergence of Dinophysis acuminata blooms and DSP toxins in shellfish in New York waters. Harmful Algae 2013, 26, 33-44. [CrossRef]

7. Wolny, J.L.; Egerton, T.A.; Handy, S.M.; Stutts, W.L.; Smith, J.L.; Whereat, E.B.; Bachvaroff, T.R.; Henrichs, D.W.; Campbell, L.; Deeds, J.D. Characterization of Dinophysis spp. (Dinophyceae, Dinophysiales) from the mid-Atlantic region of the US. J. Phycol. 2020, 56, 404-424. [CrossRef]

8. Zendong, Z.; Sibat, M.; Herrenknecht, C.; Hess, P.; McCarron, P. Relative molar response of lipophilic marine algal toxins in liquid chromatography electrospray ionization mass spectrometry. Rapid. Comm. Mass Spec. 2017, 31, 1453-1461. [CrossRef]

9. Yasumoto, T.; Oshima, Y.; Yamaguchi, H. Occurrence of a new type of shellfish poisoning in the Tohoku district. Bull. Jpn. Soc. Sci. Fish. 1978, 44, 1249-1255. [CrossRef]

10. Yasumoto, T.; Oshima, Y.; Sugawara, W.; Fukuyo, Y.; Oguri, H.; Igarashi, T.; Fujita, N. Identification of Dinophysis firtii as the causative organism of diarrhetic shellfish poisoning. Bull. Jpn. Soc. Sci. Fish 1980, 46, 1405-1411. [CrossRef]

11. Schmitz, F.J.; Prasad, R.S.; Gopichand, Y.; Hossain, M.B.; van der Helm, D. Acanthifolicin, a new episulfide-containing polyether carboxylic acid from extracts of the marine sponge Pandaros acanthifolium. J. Am. Chem. Soc. 1981, 103, 2467-2469. [CrossRef]

12. Tachibami, K.; Scheuer, P.J.; Tsukitani, Y.; Kikuchi, H.; Van Engen, D.; Clardy, J.; Gopichand, Y.; Schmitz, F.J. Okadaic acid, a cytotoxic polyether from two marine sponges of the genus Halichondria. J. Am. Chem. Soc. 1981, 103, 2469-2471. [CrossRef]

13. Murata, M.; Shimatani, M.; Sugitani, H.; Oshima, Y.; Yasumoto, T. Isolation and structural elucidation of the causative toxin of diarrhetic shellfish poisoning. Bull. Jpn. Soc. Sci. Fish. 1982, 48, 549-552. [CrossRef]

14. Murakami, Y.; Oshima, Y.; Yasumoto, T. Identification of Okadaic acid as a toxic component of a marine dinoflagellate Prorocentrum lima. Bull. Jpn. Soc. Sci. Fish 1982, 48, 69-72. [CrossRef]

15. Yasumoto, T.; Murata, M.; Oshima, Y.; Sano, M. Diarrhetic shellfish toxins. Tetrahedron 1985, 41, $1019-1025$. [CrossRef]

16. Kumagi, M.; Yanagi, T.; Murata, M.; Yasumoto, T.; Kat, M.; Lassus, P.; Rodriguez-Vasquez, J.A. Okadaic acid as the causative toxin of diarrhetic shellfish poisoning in Europe. Agric. Biol. Chem. 1986, 50, 2853-2857.

17. Hu, T.; Doyle, J.; Jackson, D.; Marr, J.; Nixon, E.; Pleasance, S.; Quilliam, M.A.; Walter, J.A.; Wright, J.L.C. Isolation of a new diarrhetic shellfish poison from Irish mussels. J. Chem. Soc. Chem. Commun. 1992, 1, $39-41$. [CrossRef]

18. Schmitz, F.J.; Yasumoto, T. The 1990 United States-Japan seminar on bioorganic marine chemistry, meeting report. J. Nat. Prod. 1991, 54, 1469-1490. [CrossRef]

19. Holmes, M.J.; Lee, F.C.; Khoo, H.W.; Ming Teo, S.L. Production of 7-deoxy-okadaic acid by a New Caledonian strain of Prorocentrum lima (Dinophyceae). J. Phycol. 2001, 37, 280-288. [CrossRef]

20. Cruz, P.G.; Hernández Daranas, A.; Fernández,J.J.; Norte, M. 19-epi-okadaic acid, A novel protein phosphatase inhibitor with enhanced selectivity. Org. Lett. 2007, 9, 3045-3048. [CrossRef]

21. Beach, D.G.; Crain, S.; Lewis, N.; LaBlanc, P.; Hardstaff, W.R.; Perez, R.A.; Giddings, S.D.; Martinez-Farina, C.E.; Stefanova, R.; Burtan, I.W.; et al. Development of certified reference materials for diarrhetic shellfish poisoning toxins. Part 1: Calibration solutions. J. AOAC Int. 2016, 99, 1151-1162. [CrossRef]

22. Takai, A.; Murata, M.; Torigoe, K.; Isobe, M.; Mieskes, G.; Yasumoto, T. Inhibitory effect of okadaic acid derivatives on protein phosphatases. Biochem. J. 1992, 284, 539-544. [CrossRef] [PubMed]

23. Sakai, R.; Rinehart, K.L. A new polyether acid from a cold water marine sponge, a Phykellia species. J. Nat. Prod. 1995, 58, 773-777. [CrossRef] [PubMed] 
24. Rao, D.V.S.; Pan, Y.; Zitko, V.; Bugden, G.; Mackeigan, K. Diarrhetic shellfish poisoning (DSP) associated with a subsurface bloom of Dinophysis norvegica in Bedford Basin, eastern Canada. Mar. Ecol. Prog. Ser. 1993, 97, 117-126.

25. Marr, J.C.; Jackson, A.E.; McLachlan, J.L. Occurrence of Prorocentrum lima, a DSP toxin-producing species from the Atlantic coast of Canada. J. Appl. Phycol. 1992, 4, 17-24. [CrossRef]

26. Quilliam, M.A.; Gilgan, M.W.; Pleasance, S.; de Freitas, A.S.W.; Douglas, D.; Fritz, L.; Hu, T.; Marr, J.C.; Smyth, C.; Wright, J.L.C. Confirmation of an incident of diarrhatic shellfish poisoning in eastern Canada. In Toxic Phytoplankton Blooms in the Sea; Smayda, T.J., Shimizu, Y., Eds.; Elsevier Science Publishers: Amsterdam, The Netherlands, 1993; pp. 547-552.

27. Morton, S.A.; Leighfield, T.A.; Haynes, B.L.; Petitpain, D.L.; Busman, M.A.; Moeller, P.D.R.; Bean, L.; McGowan, J.; Hurst, J.W., Jr.; Van Dolah, F.M. Evidence of diarrhetic shellfish poisoning along the coast of Maine. J. Shellfish Res. 1999, 18, 681-686.

28. Maranda, L.; Corwin, S.; Hargraves, P.E. Prorocentrum lima (Dinophyceae) in northeastern USA coastal waters: I. Abundance and distribution. Harmful Algae 2007, 6, 623-631. [CrossRef]

29. Maranda, L.; Corwin, S.; Dover, S.; Morton, S.L. Prorocentrum lima (Dinophyceae) in northeastern USA coastal waters: II. Toxin loads in the epibiota and in shellfish. Harmful Algae 2007, 6, 632-641. [CrossRef]

30. NSSP (National Shellfish Sanitation Program). Guide for the Control of Molluscan Shellfish: 2017 Revision. Available online: http://www.fda.gov/Food/GuidanceRegulation/FederalStateFoodPrograms/ucm2006754. htm (accessed on 8 June 2020).

31. Botana, L.M.; Hess, P.; Munday, R.; Nathalie, A.; Degrasse, S.L.; Feeley, M.; Suzuki, T.; van der Berg, M.; Fattori, V.; Gamarro, E.G.; et al. Derivation of toxicity equivalency factors for marine biotoxins associated with bivalve molluscs. Trends Food Sci. Tech. 2017, 59, 15-24. [CrossRef]

32. Schultz, D.; Campbell, L.; Kudela, R.M. Trends in Dinophysis adundance and diarrhetic shellfish toxin levels in California mussels (Mytilus californianus) from Monterey Bay, California. Harmful Algae 2019, 88, 1-12. [CrossRef]

33. Séchet, V.; Safran, P.; Hovgaard, P.; Yasumoto, T. Causative species of diarrhetic shellfish poisoning (DSP) in Norway. Mar. Biol. 1990, 105, 269-274. [CrossRef]

34. Carpenter, E.J.; Janson, S.; Boje, R.; Pollehne, P.; Chang, J. The dinoflagellate Dinophysis norvegica: Biological and ecological observations in the Baltic Sea. Eur. J. Phycol. 1995, 30, 1-9. [CrossRef]

35. Reguera, B.; Velo-Suárez, L.; Raine, R.; Park, M.G. Harmful Dinophysis species: A review. Harmful Algae 2012, 14, 87-106. [CrossRef]

36. Reguera, B.; Riobó, P.; Rodriguez, F.; Díaz, P.A.; Pizarro, G.; Paz, B.; Franco, J.M.; Blanco, J. Dinophysis toxins: Causative organisms, distribution, and fate in shellfish. Mar. Drugs 2014, 12, 394-461. [CrossRef] [PubMed]

37. Miles, C.O.; Wilkins, A.L.; Samdall, I.A.; Sandvik, M.; Petersen, D.; Quilliam, M.A.; Naustvoll, L.J.; Rundberget, T.; Torgersen, T.; Hovgaard, P.; et al. A novel pectenotoxin, PTX-12, in Dinophysis Spp. and shellfish in Norway. Chem. Res. Toxicol. 2004, 17, 1423-1433. [CrossRef] [PubMed]

38. Suzuki, T.; Miyazono, A.; Baba, K.; Sugawara, R.; Kamiyama, T. LC-MS/MS analysis of okadaic acid analogs and other lipophilic toxins in single-cell isolates of several Dinophysis species collected in Hokkaido, Japan. Harmful Algae 2009, 8, 233-238. [CrossRef]

39. Holmes, C.F.B. Liquid chromatography-linked protein phosphatase bioassay; a highly sensitive marine bioscreen for okadaic acid and related diarrhetic shellfish toxins. Toxicon 1991, 29, 469-477. [CrossRef]

40. McCarron, P.; Wright, E.; Quilliam, M.A. Liquid chromatography/mass spectrometry of domoic acid and lipophilic shellfish toxins with selected reaction monitoring and optional confirmation by library searching of product ion spectra. J. AOAC Int. 2014, 97, 316-324. [CrossRef]

41. Blay, P.; Hui, J.P.M.; Chang, J.M.; Melanson, J.E. Screening for multiple classes of marine biotoxins by liquid chromatography-high resolution mass spectrometry. Anal. Bioanal. Chem. 2011, 400, 577-585. [CrossRef]

42. Liquid Chromatography Tandem Mass Spectrometry (LC-MS/MS) Method for the Determination of Diarrhetic Shellfish Poisoning (DSP) Toxins in Shellfish. Available online: http://www.issc.org/Data/Sites/1/media/002017biennialmeeting/--taskforcei2017/17-103-supporting-documentation.pdf (accessed on 8 June 2020).

43. Tong, M.; Kulis, D.M.; Fux, E.; Smith, J.L.; Hess, P.; Zhou, Q.; Anderson, D.M. The effects of growth phase and light intensity on toxin production by Dinophysis acuminata from the northeastern United States. Harmful Algae 2011, 10, 254-264. [CrossRef] 
44. Nishitani, G.O.H.; Nagai, S.; Sakiyama, S.; Kamiyama, T. Successful cultivation of the toxic dinoflagellate Dinophysis caudata (Dinophyceae). Plankton Benthos Res. 2008, 3, 78-85. [CrossRef]

45. Park, M.G.; Kim, S.; Kim, H.S.; Myung, G.; Kang, Y.G.; Yih, W. First successful culture of the marine dinoflagellate Dinophysis acuminata. Aquat. Microb. Ecol. 2006, 45, 101-106. [CrossRef]

46. Hackett, J.D.; Tong, M.; Kulis, D.M.; Fux, E.; Hess, P.; Bire, R.; Anderson, D.M. DSP toxin production de novo in cultures of Dinophysis acuminata (Dinophyceae) from North America. Harmful Algae 2009, 8, 873-879. [CrossRef]

47. Anderson, D.M.; Kulis, D.M.; Doucette, G.J.; Gallagher, J.C.; Balech, E. Biogeography of toxic dinoflagellates in the genus Alexandrium from the northeastern United States and Canada. Mar. Biol. 1994, 120, 467-478. [CrossRef]

48. Hattenrath-Lehmann, T.K.; Lusty, M.W.; Wallace, R.B.; Haynes, B.; Wang, Z.; Broadwater, M.; Deeds, J.R.; Morton, S.L.; Hastback, W.; Porter, L.; et al. Evaluation of Rapid, Early Warning Approaches to Track Shellfish Toxins Associated with Dinophysis and Alexandrium Blooms. Marine Drugs 2018, 16, 28. [CrossRef] [PubMed]

49. Onofrio, M.D.; Mallet, C.R.; Place, A.R.; Smith, J.L. A screening tool for the direct analysis of marine and freshwater phycotoxins in organic SPATT extracts from the Chesapeake Bay. Toxins 2020, 12, 322. [CrossRef]

(C) 2020 by the authors. Licensee MDPI, Basel, Switzerland. This article is an open access article distributed under the terms and conditions of the Creative Commons Attribution (CC BY) license (http://creativecommons.org/licenses/by/4.0/). 